\title{
Practicing Renal Transplant Pathology in a Developing Country: Challenges and Opportunities
}

\section{Muhammed Mubarak*}

Associate professor, Histopathology Department, Sindh Institute of Urology and Transplantation, Karachi, Pakistan

\section{Practicing Renal Transplant Pathology in a Developing Country: Challenges and Opportunities}

Renal allograft biopsy plays a crucial role in the diagnosis and management of renal allograft dysfunction in renal transplant recipients $[1,2]$. With the exponential rise in the number of renal transplants taking place throughout the world, the renal transplant pathology has achieved a pre-eminent role among the multidisciplinary team caring for these patients. Renal transplant pathology is also a rapidly evolving subspecialty of renal pathology. Prior to 1991, there was a lack of standardized terminology and criteria for the pathologic diagnosis of renal transplant lesions [3,4]. With the promulgation of Banff working formulation for the diagnosis and categorization of rejection, it has become a major standard setting instrument for the interpretation and reporting of renal allograft pathology throughout the world [5]. The first Banff meeting took place in 1991 and the first detailed classification was published in 1993 [6]. Since then, regular meetings with periodic updates of the classification at two yearly intervals have lead to some major modifications of the original schema [7-13]. However, the basic construct has remained the same over the years. The first major modification took place in 1997 with the merger of two major classifications widely used at that time, both in clinical practice and in antirejection therapy trials; the Banff 93-95 classification and the National Institute of Health (NIH)-sponsored collaborative clinical trials in transplantation (CCTT) modification of this classification $[7,14]$. Specimen adequacy criteria were made more stringent, grades of rejection were changed to types of rejection, and antibody mediated rejection (AMR) was better defined. Numerous independent studies throughout the world have proved the clinical validity and fair reproducibility of the Banff 97 classification [5]. The schema has also been endorsed by Food and Drug Administration (FDA) and other regulatory agencies for use in the international clinical trials of new immunosuppressive/antirejection agents. It may be noted that the interpretation of renal transplant lesions on renal allograft biopsies in earlier Banff schemas was based predominantly on light microscopy (LM) and the tinctorial stains. With further modifications in the Banff classification, the ancillary techniques of immunohistochemistry (IHC) and electron microscopy (EM) were also recommended for complete pathological evaluation of the transplant lesions [8-13]. The more sophisticated approach for the pathological evaluation allows refinement in the diagnostic categories and specific therapeutic options. The major modifications have occurred in the category of AMR, chronic allograft nephropathy (CAN), and the scoring of total interstitial inflammation (ti) [8-13]. IHC for C4d and polyoma virus infection has been made mandatory for all dysfunctional graft biopsies. EM is still an optional application. The use of omicstechnologies including genomics and proteomics in further refining the diagnostic criteria is being actively explored in both experimental and clinical settings [11]. The time is not far away when a combination of morphological changes on renal allograft biopsies with the molecular markers will be a feasible option to arrive at the most precise diagnosis of the transplant lesions. The routine use of such ancillary techniques in the study of renal transplant biopsies can be implemented without much difficulty in developed countries. However, there are major obstacles in the way of complete implementation of the updated Banff classification in developing countries. The procurement of C4d and SV40 large $\mathrm{T}$ antigen antibodies is either difficult or incurs prohibitive cost. EM is not available in majority of the renal transplant centers in low income countries. The access to molecular and omics-technologies is also beyond the reach of most laboratories in underdeveloped countries. Even good quality processing and staining reagents are not available. Last, but not the least, the trained manpower, including both the transplant pathologists and technologists, is not readily available in most centers in the developing countries.

Thus, the practical application of updated Banff classification in developing countries not only poses the above mentioned challenges but also offers some opportunities. The later include an active collaboration between transplant centers in the developing countries with those in the developed world [15]. Areas of collaboration may include imparting training to the relevant medical personnel, supply of reagents and offer of free diagnostic service for the difficult or problematic cases. In this context, there is a long legacy in the field of renal pathology of providing free and humanitarian services to the lowincome countries [16]. This option is increasingly becoming difficult to fulfill these days [16]. As an alternate option, developing countries can establish national reference centers for renal transplant pathology where specimens from all over the country can be sent and studied by the state of the art methodology available in developed countries. This will help in the achievement of the ultimate goal of Banff schema, which is the optimal patient care.

\section{References}

1. Colvin RB (1996) The renal allograft biopsy. Kidney Int 50: 1069-1082.

2. Kazi J, Mubarak M (2012) Biopsy findings in renal allograft dysfunction in a live related renal transplant program. J Transplant Tech Res 2: 108.

3. Farnsworth A, Hall BM, Ng AB, Duggin GG, Horvath JS, et al. (1984) Renal biopsy morphology in renal transplantation. A comparative study of the lightmicroscopic appearances of biopsies from patients treated with cyclosporin A or azathioprine prednisone and antilymphocyte globulin. Am J Surg Pathol 8: 243-252.

4. Bergstrand A, Bohman SO, Farnsworth A, Gokel JM, Krause PH, et al. (1985) Renal histopathology in kidney transplant recipients immunosuppressed with cyclosporine A: results of an international workshop. Clin Nephrol 24: 107-119.

5. Solez K (2010) History of the Banff classification of allograft pathology as it approaches its 20th year. Curr Opin Organ Transplant 15: 49-51.

6. Solez K, Axelsen RA, Benediktsson H, Burdick JF, Cohen AH, et al. (1993)

*Corresponding author: Muhammed Mubarak, Histopathology Department Sindh Institute of Urology and Transplantation, Karachi-74200, Pakistan, Tel: 009221 99215752; Fax: 009221 32726165; E-mail: drmubaraksiut@yahoo.com

Received October 25, 2012; Accepted November 27, 2012; Published November 29, 2012

Citation: Mubarak M (2012) Practicing Renal Transplant Pathology in a Developing Country: Challenges and Opportunities. J Transplant Technol Res 2:e118. doi:10.4172/2161-0991.1000e118

Copyright: @ 2012 Mubarak M. This is an open-access article distributed under the terms of the Creative Commons Attribution License, which permits unrestricted use, distribution, and reproduction in any medium, provided the original author and source are credited. 
International standardization of criteria for the histologic diagnosis of renal allograft rejection: the Banff working classification of kidney transplant pathology. Kidney Int 44: 411-422.

7. Racusen LC, Solez K, Colvin RB, Bonsib SM, Castro MC, et al. (1999) The Banff 97 working classification of renal allograft pathology. Kidney Int 55: 713723.

8. Racusen LC, Colvin RB, Solez K, Mihatsch MJ, Halloran PF, et al. (2003) Antibody-mediated rejection criteria —an addition to the Banff 97 classification of renal allograft rejection. Am J Transplant 3: 708-714.

9. Racusen LC, Halloran PF, Solez K (2004) Banff 2003 meeting report: new diagnostic insights and standards. Am J Transplant 10: 1562-1566.

10. Solez K, Colvin RB, Racusen LC, Sis B, Halloran PF, et al. (2007) Banff '05 meeting report: differential diagnosis of chronic allograft injury and elimination of chronic allograft nephropathy (CAN). Am J Transplant 7: 518-526.

11. Solez K, Colvin RB, Racusen LC, Haas M, Sis B, et al. (2008) Banff' 07 classification of renal allograft pathology: updates and future directions. Am J Transplant 8: 753-760.

12. Sis B, Mengel M, Haas M, Colvin RB, Halloran PF, et al. (2010) Banff '09 meeting report: antibody mediated graft deterioration and implementation of Banff working groups. Am J Transplant 10: 464-471.

13. Mengel M, Sis B, Haas M, Colvin RB, Halloran PF, et al. (2012) Banff 2011 Meeting report: new concepts in antibody-mediated rejection. Am J Transplant 12: $563-570$.

14. Colvin RB, Cohen AH, Saiontz C, Bonsib S, Buick M, et al. (1997) Evaluation of pathologic criteria for acute renal allograft rejection: Reproducibility, sensitivity, and clinical correlation. J Am Soc Nephrol 8: 1930-1941.

15. Arias LF, Arteta AA, Giraldo RD (2007) Renal allograft rejection: difficulties in biopsy diagnosis in low-income countries. Am J Transplant 7: 2835

16. Solez K (2007) Making global transplantation pathology standards truly global. Am J Transplant 7: 2834 